Tema: Solidificação / Lingotamento

\title{
GANHOS OBTIDOS ATRAVÉS DO ENVIO DE PLACAS DO LINGOTAMENTO CONTÍNUO DIRETAMENTE PARA O LAMINADOR DE TIRAS A QUENTES NA ARCELORMITTAL TUBARÃO*
}

\author{
Marcelo Macedo Fialho ${ }^{1}$ \\ José Carlos de Pontes Junior ${ }^{2}$ \\ João Augusto Guilherme Barros ${ }^{3}$ \\ Leonardo Lira Alves ${ }^{4}$ \\ Renato Fonseca Cortes ${ }^{5}$ \\ Marcelo Augusto Bittencourt Flores ${ }^{6}$
}

\section{Resumo}

No processo produtivo de aço, as empresas buscam continuamente a redução do custo de produção. Isto pode ocorrer através de diversas formas, tendo como as principais, o ganho de rendimento, o aumento de produtividade, a redução do homem hora aplicado e a redução do custo de matéria prima. Objetivando reduzir o custo de produção integrado placa bobina, a ArcelorMittal Tubarão busca aumentar o percentual de placas enviadas diretamente do Lingotamento Contínuo de Placas para o Laminador de Tiras a Quente. Os ganhos se dão, em primeiro plano, através da redução da intervenção nas placas aumentando o rendimento de placa e exigindo menos mão de obra para o corte e escarfagem de placa e, em segundo plano, através do aumento da temperatura média de enfornamento, propiciando maior produtividade no laminador de tiras a quente e menor consumo de energia para realizar o pré-aquecimento da placa antes do processo de laminação. Somado a isto, a maior disponibilidade de placas no pátio do LTQ, aumenta a chance de laminação exigindo menos paradas do LTQ e aumentando a produção. Os ganhos estimados com o projeto, apenas no que diz respeito a redução de custo de condicionamento são de 6MUSD/ano.

Palavras-chave: Enformamento a Quente; Conexão direta LC-LTQ.

\section{HOT CHARGE AT ARCELORMITTAL TUBARÃO: GAINS AFTER INCREASING THE PERCENTAGE OF SLABS SENT DIRECTELY FROM CONTINUOS CASTING TO HOT STRIP MILL SLAB YARD}

\begin{abstract}
In Steelmaking process, the plants continuously strives for production cost reduction. It can be made through many ways like yield improvement, productivity increase, Labor force reduction or reduction of raw materials cost. Aiming to reduce the production cost of slabs and coils, ArcelorMittal Tubarao pursuit to increase the percentage of slabs sent directly from Continuous Casting Machine to Hot Strip Mill. The gains come firstly from reduction of conditioning, increasing the slab yield and reducing the labor force needed to scarfing and cutting slabs, and secondly, through the increase of hot charge helping more productivity in the Hot Strip Mill and demanding less energy to preheat the slabs before rolling. It is also important, the more availability of slabs in Hot Strip Mill slab yard, helping rolling schedule, requiring less HSM stoppages and thus, increasing production. The estimated gains with the project considering only the reduction of cost in the conditioning is 6MD/year.

Keywords: Hot charge; Connection CC-HSM.

\footnotetext{
Especialista da Área de Confiabilidade de Produção de Placas, ArcelorMittal Tubarão, Serra, ES, Brasil. Gerente da Área de Confiabilidade de Produção de Placas, ArcelorMittal Tubarão, Serra, ES, Brasil. Gerente da Área de Confiabilidade de Produção de Bobinas, ArcelorMittal Tubarão, Serra, ES, Brasil.

Especialista da Área de Confiabilidade de Produção de Bobinas, ArcelorMittal Tubarão, Serra, ES, Brasil.
}

5 Especialista da Área de Confiabilidade Produção de Placas, ArcelorMittal Tubarão, Serra, ES, Brasil.

6 Especialista da Área Automação de Processos, ArcelorMittal Tubarão, Serra, ES, Brasil.
\end{abstract}

\footnotetext{
* Contribuição técnica ao $45^{\circ}$ Seminário de Aciaria - Internacional, 25 a 28 de maio de 2014, Porto Alegre, RS, Brasil.
} 


\section{INTRODUÇÃO}

A interface entre Lingotamento Contínuo de Placas e Laminador de Tiras a Quente é presente em cerca de $40 \%$ da produção de aço mundial como mostra a Figura 1 [1].

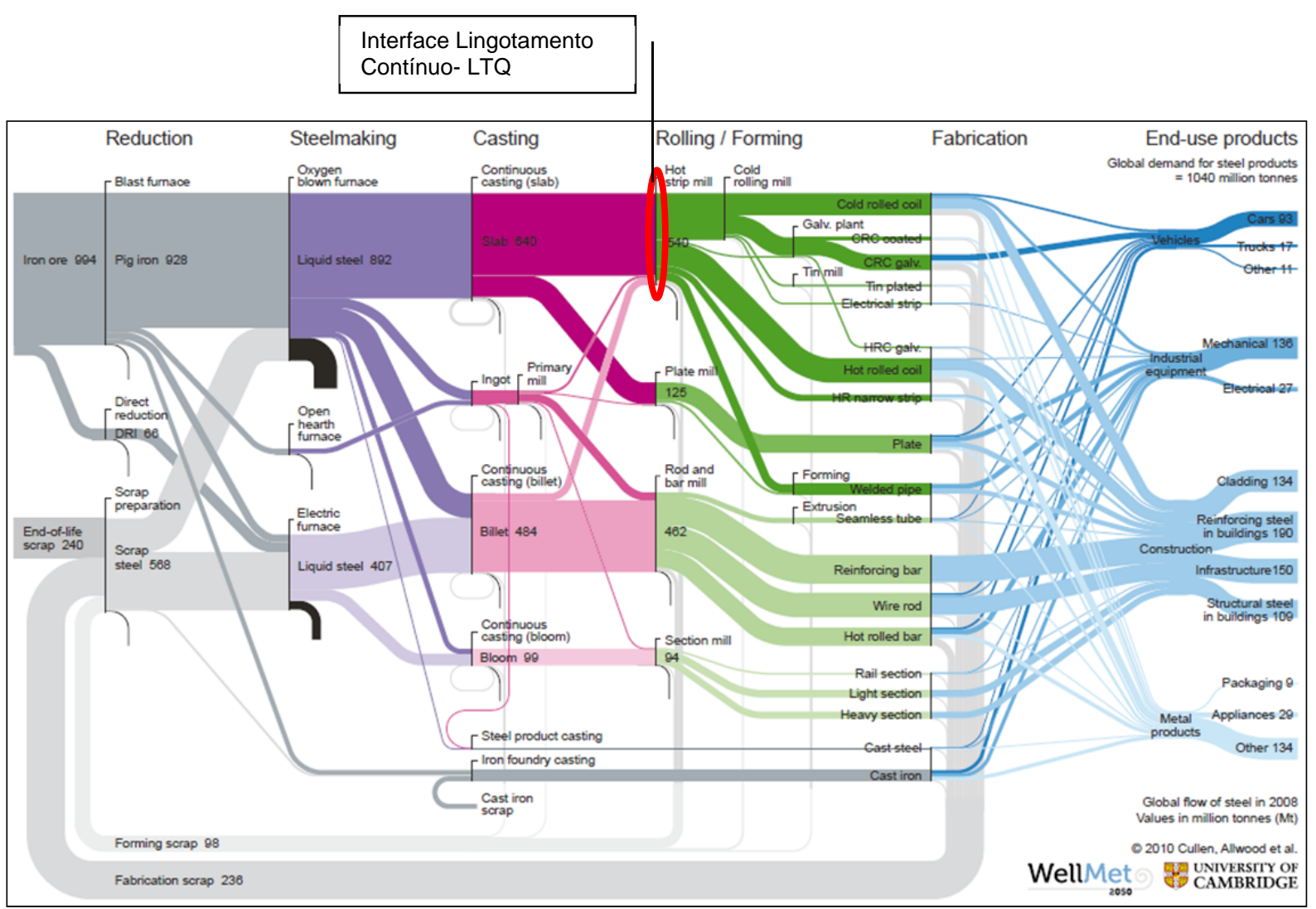

Figura 1. Etapas da produção de aço até o produto final [1].

A etapa de transição das placas do lingotamento contínuo até o forno de aquecimento do laminador é responsável por perdas no processo, sendo elas:

- Perda Térmica devido ao resfriamento da placa que fica em contato com a atmosfera em menor temperatura;

- Perda de rendimento metálico causada, basicamente, pela intervenção nas placas devido a eventos de qualidade. Esta intervenção é realizada através de corte e escarfagem.

Os dois fatores mencionados têm implicações financeiras para a empresa. A perda térmica gera um maior gasto de energia do forno para o aquecimento da placa antes da laminação. A Figura 2 mostra um gráfico que relaciona a temperatura de enfornamento da placa e consumo específico de energia [2]. A perda metálica reduz o volume do produto formando sucata gerada.

* Contribuição técnica ao $45^{\circ}$ Seminário de Aciaria - Internacional, 25 a 28 de maio de 2014, 

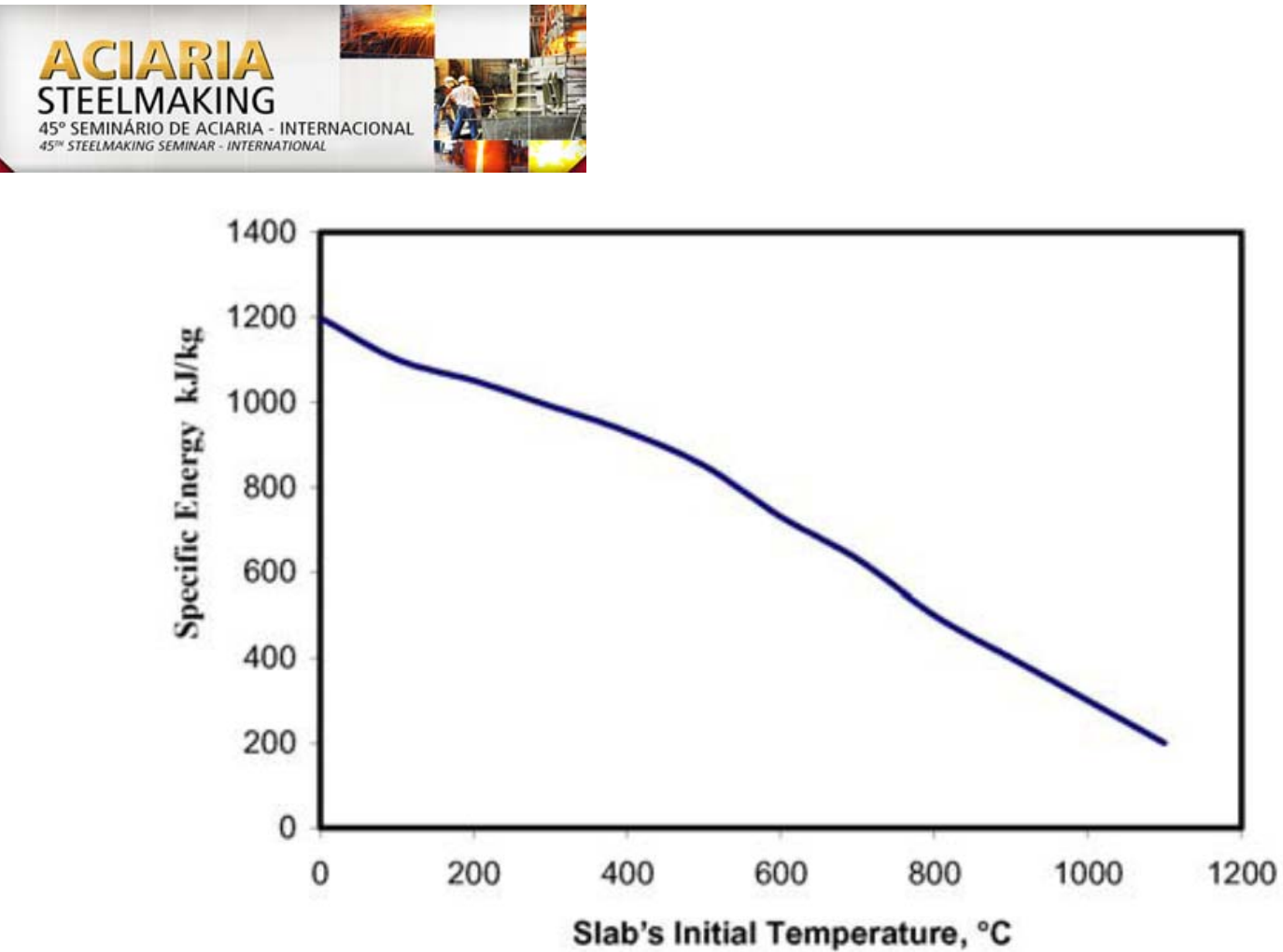

Figura 2. Relação entre consumo específico de energia e temperatura inicial da placa.

\section{MATERIAL E MÉTODOS}

O desenvolvimento do projeto só foi possível devido ao tratamento das informações obtidas a partir das ocorrências operacionais e de processo. Para tanto, foi necessário o desenvolvimento de um sistema de aquisição de dados o qual utilizava três plataformas, chamadas nível 1, 2 e 3. O esquema do sistema de aquisição de dados é mostrado na Figura 3.

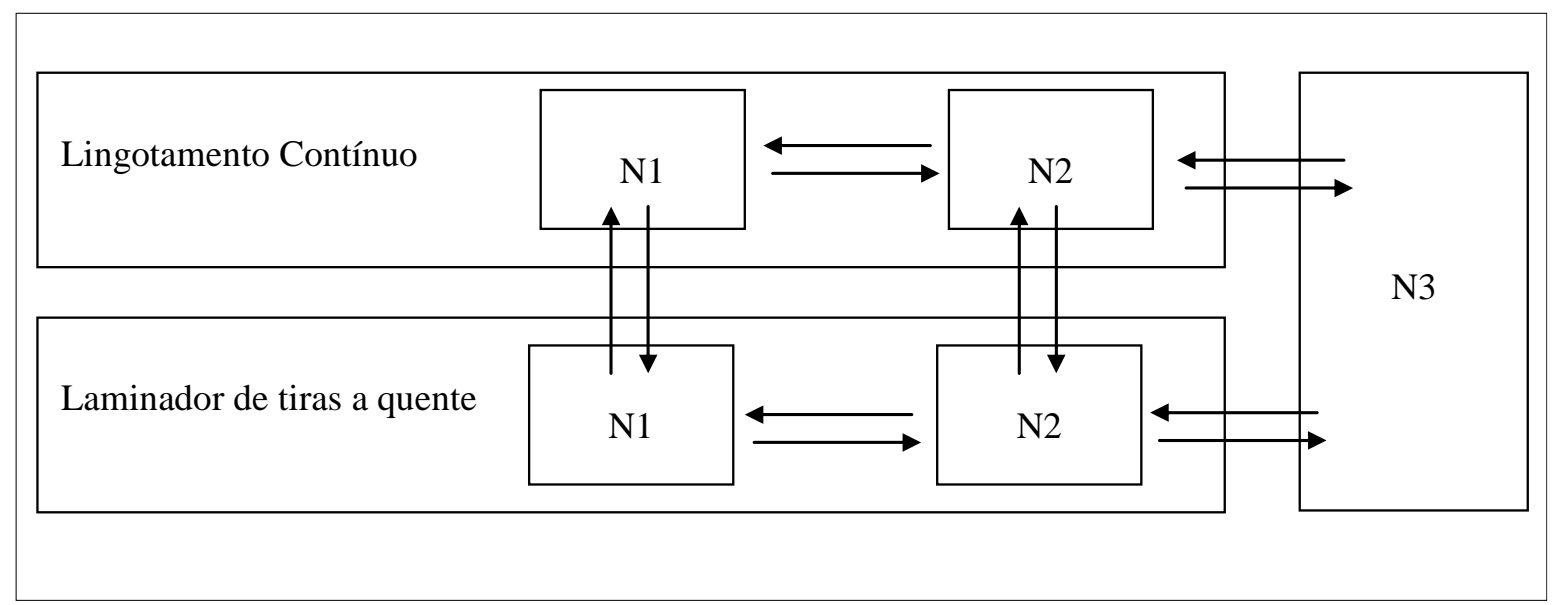

Figura 3. Plataformas de aquisição de informação do processo.

As características das plataformas são as seguintes:

Nível 1: Obtém informações diretas do processo através de dispositivos de medição como encoders, termopares, sensores, etc. Trabalha as informações através de controladores de processamento lógico (PLC).

* Contribuição técnica ao 450 Seminário de Aciaria - Internacional, 25 a 28 de maio de 2014, 


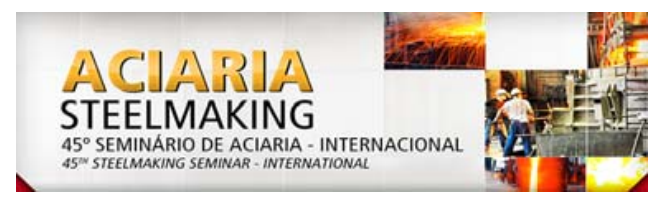

Nível 2: Recebe informações de especificação de produção do nível 3 e elabora a instrução de produção para a operação. Atribui um número de identificação para cada placa produzida. Compara os dados de especificação com os dados recebidos pelo nível 1 e realiza julgamento.

Nível 3: Envia as especificações de produção para o nível 2 e recebe informação final das características das placas. Armazena as informações recebidas do nível 2 em um banco de dados para consulta e análise.

O ponto chave da estrutura de aquisição de dados é conhecer os motivos de desvio de uma placa para o condicionamento. Estes motivos são carregados no sistema de três formas:

- Carregamento automático- É realizado de acordo com o julgamento do nível 2, comparando a especificação do pedido e os dados reais da placa. Estes desvios estão relacionados à qualidade do produto como eventos de qualidade do processo e desvios dimensionais.

- Carregamento do motivo pelo operador do contínuo- Ocorre quando há alguma anormalidade que não pode ser detectada pelo nível 2. Estes motivos estão relacionados com falhas de equipamento na mesa de saída do contínuo como marcador e desrebarbador ou problemas de qualidade identificados na inspeção visual.

- Carregamento do motivo pelo operador do LTQ- Estes motivos estão relacionados com falhas nos equipamentos do LTQ que permitem a translação das placas para o seu pátio como ponte rolante e mesa de rolos. Estão também relacionados a estes motivos a incapacidade de recebimento das placas devido indisponibilidade de ponte rolante em função da realização de manobras que concorrem com o recebimento (ex. Carregamento do forno do LTQ).

Os motivos de desvio são codificados e registrados no nível 2. A Tabela 1 mostra exemplos de motivos de desvio.

Tabela 1. Exemplo de motivos de desvio e seus códigos

\begin{tabular}{|l|l|l|}
\hline Descrição & $\begin{array}{l}\text { Carregamento no } \\
\text { sistema }\end{array}$ & $\begin{array}{l}\text { Código do motivo } \\
\text { de desvio }\end{array}$ \\
\hline Evento de qualidade restritivo & Automático & E1 \\
\hline Mudança de largura fora de tolerância & Automático & I1 \\
\hline Falha no marcador & $\begin{array}{l}\text { Via operador do } \\
\text { lingotamento }\end{array}$ & 20 \\
\hline Falha no desrebarbador & $\begin{array}{l}\text { Via operador do } \\
\text { lingotamento }\end{array}$ & 30 \\
\hline $\begin{array}{l}\text { Indisponibilidade de ponte rolante do } \\
\text { LTQ- Movimentações excessivas }\end{array}$ & Via operador do LTQ & TD \\
\hline Parada não programada da mesa do LTQ & Via operador do LTQ & TI \\
\hline
\end{tabular}

A Figura 4 lista as placas de uma corrida e o destino final da placa, LTQ (L) ou condicionamento (C). No caso de placas que foram para o condicionamento, um motivo de desvio é atribuído a ela.

* Contribuição técnica ao 45 Seminário de Aciaria - Internacional, 25 a 28 de maio de 2014, 


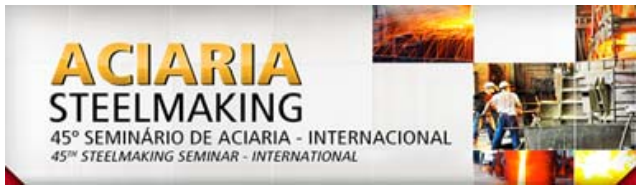

\begin{tabular}{|c|c|c|c|c|c|c|c|c|c|c|c|c|c|c|c|c|c|c|c|}
\hline Corrida & $3=35$ & $5240=5$ & $9=$ & & Selecio & nar & & $\begin{array}{l}\text { riar } \\
\text { laca }\end{array}$ & & & & $\begin{array}{l}\text { Alter } \\
\text { Pla }\end{array}$ & & & Aprovar & & Armazena & & Canc \\
\hline Pedido 515 & 50 & adrao $\mathrm{C}$ & & A.A07: & $55 \mathrm{Y} 1 \mathrm{~F} 3$ & & PEX /IE & & & & & & & & Varo & & orove & ador & 13 \\
\hline Placas & $\overline{\mathrm{COl}}$ & ond. & 02 & LTQ & 10 & & & & & & & & & Birev & & 06 & & & Comen \\
\hline & Larg & Comp & $\mathbf{c}$ & Comp & & $\mathbf{c}$ & Comp & Sucata & Peso: & Sucata & B & Class & & No & Cod Tivo & Mar & Destino & & \\
\hline Placao & \begin{tabular}{|c} 
Quente \\
mm
\end{tabular} & $\begin{array}{c}\text { Quente } \\
\text { mm }\end{array}$ & & \begin{tabular}{|l|} 
Inters. \\
mon
\end{tabular} & $\begin{array}{c}\text { Peso } \\
\mathrm{kg}\end{array}$ & & $\frac{\text { Base }}{\mathrm{mm}}$ & \begin{tabular}{|c|} 
Topo \\
$\mathrm{mm}$ \\
\end{tabular} & $\begin{array}{c}\text { Base } \\
\mathrm{kg}\end{array}$ & \begin{tabular}{|c|} 
Topo \\
$\mathrm{kg}$ \\
\end{tabular} & $\begin{array}{l}\mathrm{a} \\
\mathrm{u} \\
\mathrm{m}\end{array}$ & $\frac{\text { Placâ }}{\operatorname{lns} / 0 \mid}$ & & Seg. & \begin{tabular}{l|l|} 
Corte & Pa \\
Ponta & caro
\end{tabular} & $\operatorname{mat}_{\substack{a \\
\text { gat }}}$ & ond. Prtual & $\begin{array}{l}\text { Motivo } \\
\text { Desvio }\end{array}$ & \\
\hline 335240901 & 1386 & 11641 & $\mathrm{~N}$ & 0 & 28030 & $\mathrm{~N}$ & & & & & & A. & & ${ }^{01} \mathrm{C}$ & ódigo d & & $\mathrm{L}$ & & S \\
\hline 335240951 & 1142 & 11640 & $\mathrm{~N}$ & 0 & 23330 & $\mathrm{~N}$ & & & & & & A. & A & & hotivo de & & \pm & & S \\
\hline 335240902 & 1386 & 11641 & $\mathrm{~N}$ & 0 & 28180 & $\mathrm{~N}$ & & & & & & A. & A & $02 \mathrm{~d}$ & esvio & & L & & $S$ \\
\hline 335240952 & 1142 & 11640 & $\mathrm{~N}$ & 0 & 23280 & $\mathrm{~N}$ & & & & & & A. & A & 52 & & S & 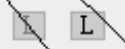 & & S \\
\hline 335240903 & 1241 & 11641 & $\mathrm{~N}$ & 0 & 27030 & $\mathrm{~N}$ & & & & & & A. & A & $03 \mathrm{r}$ & & & $-\mathrm{C}$ & I1 & $\mathrm{N}$ \\
\hline 335240953 & 1142 & 11640 & $\mathrm{~N}$ & 0 & 23300 & $\mathrm{~N}$ & & & & & & A. & A & $53 \frac{7}{n}$ & & & L) & & S \\
\hline 335240904 & 1142 & 11641 & N & 0 & 23480 & $\mathrm{~N}$ & & & & & & $\mathrm{~A}$ & A & 04 & Jesvad & 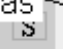 & $L \rightarrow C$ & I1 & $N$ \\
\hline 335240954 & 1142 & 11643 & $\mathrm{~N}$ & 0 & 23270 & $\mathrm{~N}$ & & & & & & A. & A & 54 & $\square \square$ & $S$ & L $\mathrm{L}$ & & S \\
\hline 335240905 & 1142 & 11643 & $\mathrm{~N}$ & 0 & 23150 & $\mathrm{~N}$ & & & & & & A & A & 05 & $\square$ & $S$ & $\mathrm{~L}$ & & S \\
\hline 335240955 & 1142 & 11641 & $\mathrm{~N}$ & 0 & 23120 & $\mathrm{~N}$ & & & & & & $\mathrm{~A}$. & A & 55 & $\square$ & $S$ & L $\mathrm{L}$ & & S \\
\hline 335240906 & 1142 & 11642 & $\mathrm{~N}$ & 0 & 23070 & $\mathrm{~N}$ & & & & & & A & A & 06 & $\mathrm{M}$ & $S$ & L $\mathrm{L}$ & & S \\
\hline 335240956 & 1142 & 11643 & $\mathrm{~N}$ & 0 & 23220 & $\mathrm{~N}$ & & & & & & A. & A & 56 & M & S & L $\quad \mathrm{L}$ & & S \\
\hline & & & $\square$ & & & $\square$ & & & & & & & 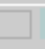 & & $\square \square$ & $\square$ & 4 & & \\
\hline & & & $\square$ & & & \begin{tabular}{|c|} 
\\
\end{tabular} & & & & & & & 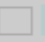 & & & & 1 & & \\
\hline & & & $\square$ & & & $\square$ & & & & & & & & & $\begin{array}{l}\text { Dest } \\
\text { orde }\end{array}$ & tino & $\begin{array}{lll}\text { De } & \text { Re }\end{array}$ & stino & \\
\hline
\end{tabular}

Figura 4.Tela do nível 2 que lista as placas de uma corrida e o destino final com os códigos do motivo de desvio.

Uma vez identificados os motivos de desvio, é possível fazer a quantificação dos principais e definir as ações possíveis para mitigá-los. Um método para priorização dos motivos é o diagrama de pareto [3].

\section{RESULTADOS}

O gráfico de pareto, (Figura 5) indicou os principais motivos de desvio e possibilitou focar as ações. Foram relacionados 36 motivos e considerados como principais 4 deles (10\% dos motivos) como mostra a Tabela 2:

Tabela 2. Principais motivos de desvio de placas para o condicionamento

\begin{tabular}{|c|c|c|}
\hline Motivo de Desvio & Principais Ações Tomadas & $\begin{array}{l}\text { Redução de } \\
\text { desvio } \\
\text { (ton/mês) }\end{array}$ \\
\hline $\begin{array}{c}\text { Mudança de } \\
\text { largura }\end{array}$ & Aumento do aceite do Taper pelo LTQ de 30 para $50 \mathrm{~mm}$ & $\begin{array}{c}28.329-> \\
22.527 \\
(-20 \%)\end{array}$ \\
\hline $\begin{array}{l}\text { Evento de } \\
\text { Qualidade }\end{array}$ & $\begin{array}{l}\text { Flexibilização dos eventos: } \\
\text { Flexibilizada a instrução de escarfagem preventiva para os } \\
\text { eventos de variação do nível do molde e argônio anormal } \\
\text { com base em benchmarks realizados no grupo. }\end{array}$ & $\begin{array}{l}24.183-> \\
13.900 \\
(-42 \%)\end{array}$ \\
\hline $\begin{array}{c}\text { Placa com } \\
\text { Rebarba }\end{array}$ & $\begin{array}{l}\text { - Produção de materiais com carbono acima 0,085\% na } \\
\text { máquina com desrebarbador mais eficiente } \\
\text { - Maior freqüência de manutenção e troca de lâminas. }\end{array}$ & $\begin{array}{l}20.037-> \\
91 \\
(-99,5 \%) \\
\end{array}$ \\
\hline $\begin{array}{l}\text { Indisponibilidade } \\
\text { de Ponte } \\
\text { Rolante do LTQ }\end{array}$ & $\begin{array}{l}\text { - Envio de duas placas do mesmo veio em sequência } \\
\text { (Permite que a ponte do LTQ capture duas placas por vez } \\
\text { por terem mesma largura) } \\
\text { - } \text { Instrução de laminação com mínimo de } 140 \text { placas- } \\
\text { Reduz trabalho diário das pontes para montagem de } \\
\text { instrução (1 por turno) } \\
\text { - } \quad \text { Aumento do buffer de recebimento das mesas do LTQ- } \\
\text { Permite maior número de placas aguardando na mesa. }\end{array}$ & $\begin{array}{l}14.855-> \\
5.151 \\
(-65 \%)\end{array}$ \\
\hline
\end{tabular}

* Contribuição técnica ao $45^{\circ}$ Seminário de Aciaria - Internacional, 25 a 28 de maio de 2014, Porto Alegre, RS, Brasil. 


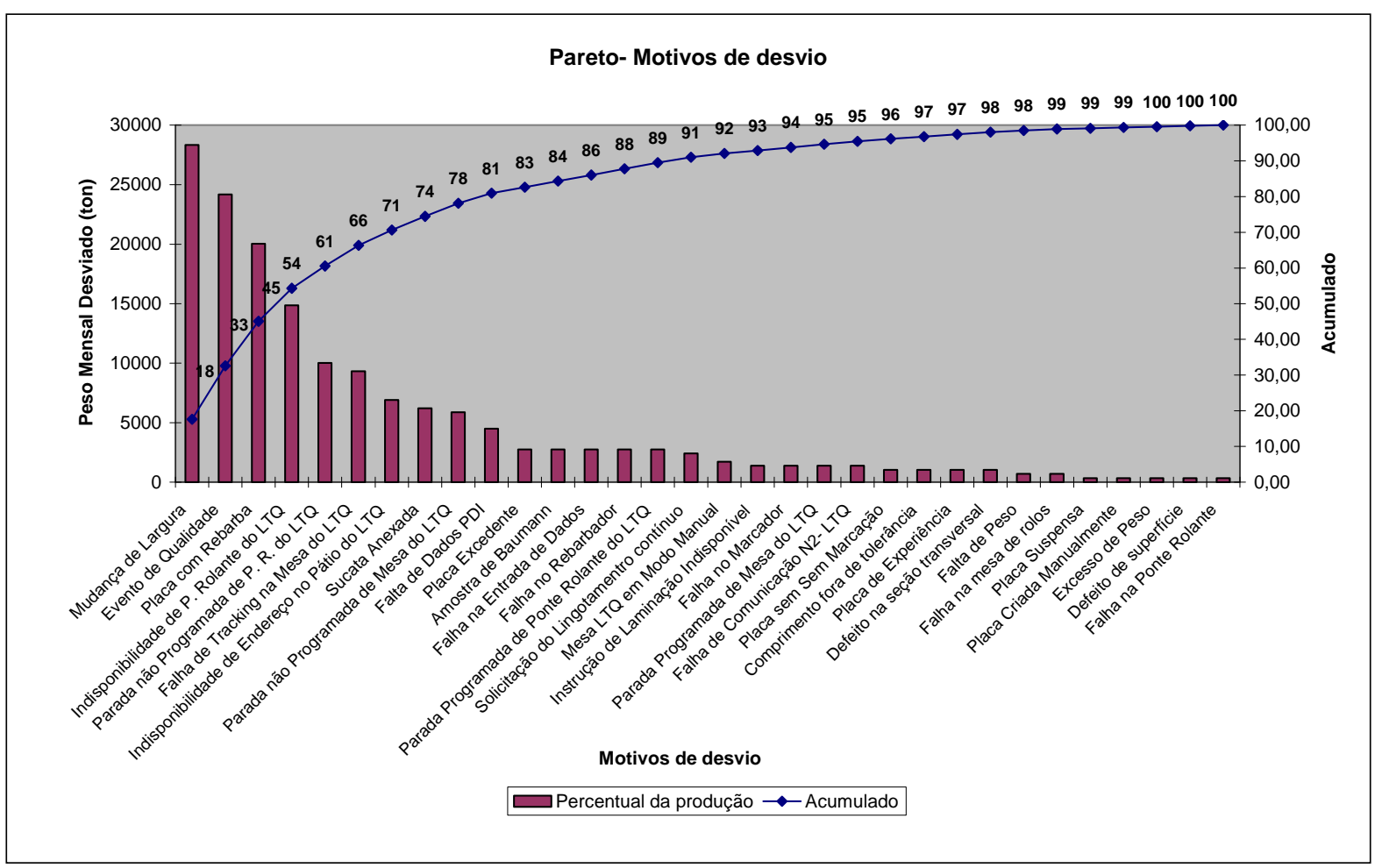

Figura 5. Pareto montado para focar o problema de desvio de placas.

A Figura 6, mostra que o índice de consecução de rota atingiu $73,2 \%$, vindo de um valor de 55,5\% em 2010.

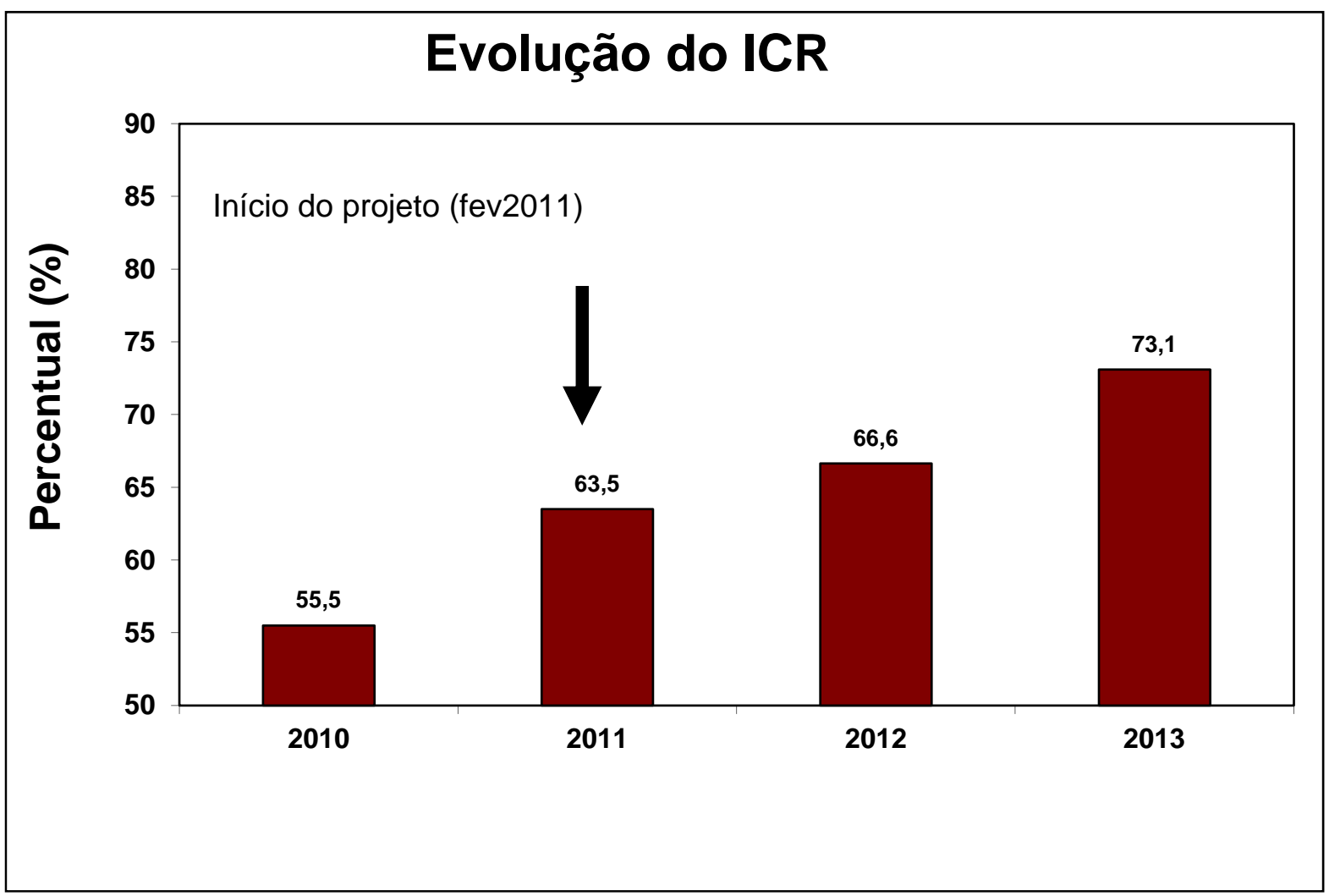

Figura 6. Evolução anual do índice de Consecução de Rota.

* Contribuição técnica ao 450 Seminário de Aciaria - Internacional, 25 a 28 de maio de 2014, Porto Alegre, RS, Brasil. 
Observou-se uma evolução significativa no percentual de placas com temperatura superior a $200^{\circ} \mathrm{C}$ (Figura 7) assim como na temperatura média de enfornamento (Figura 8).

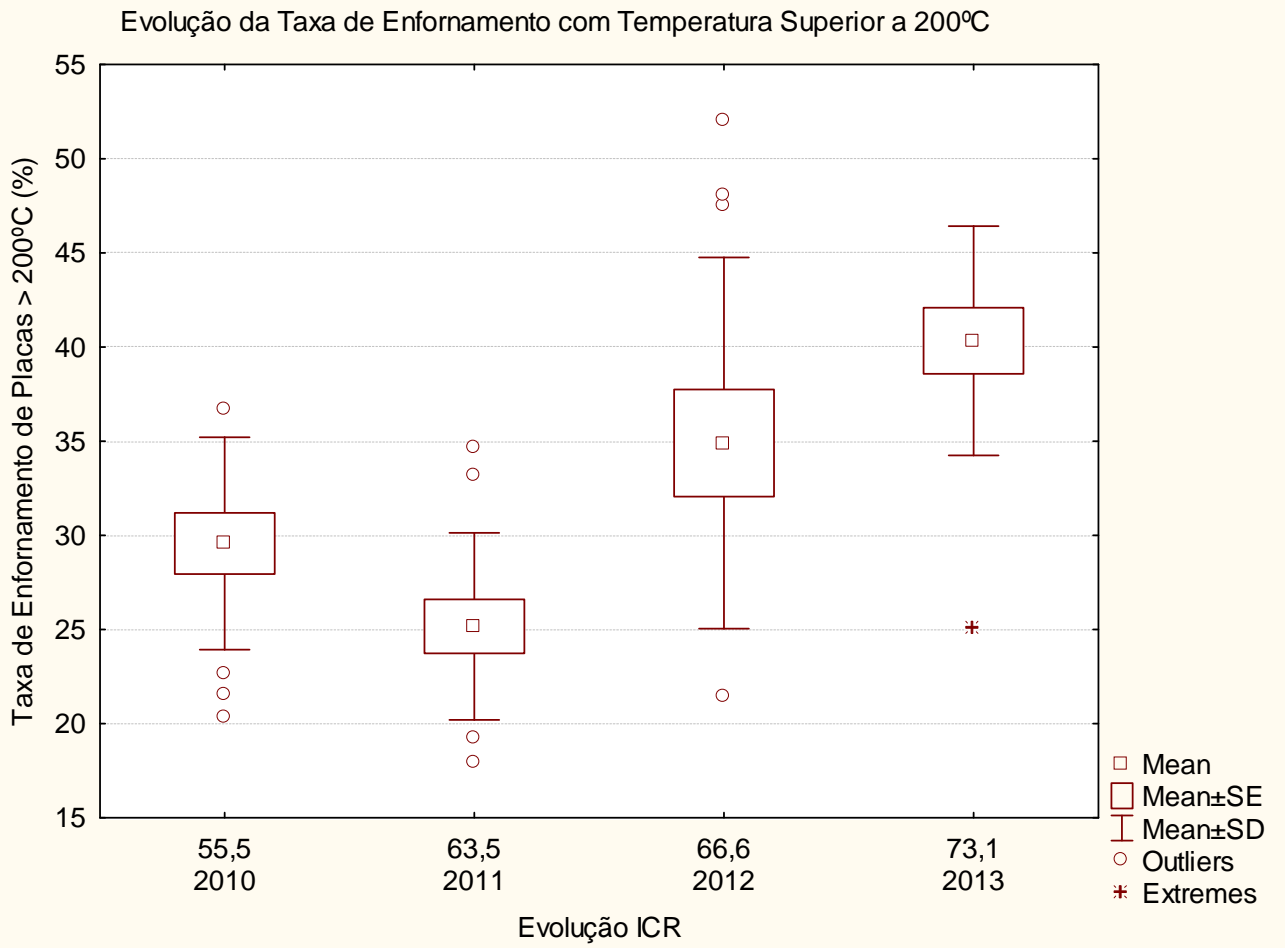

Figura 7. Evolução anual da taxa de enfornamento de placas com temperatura superior a $200^{\circ} \mathrm{C}$.

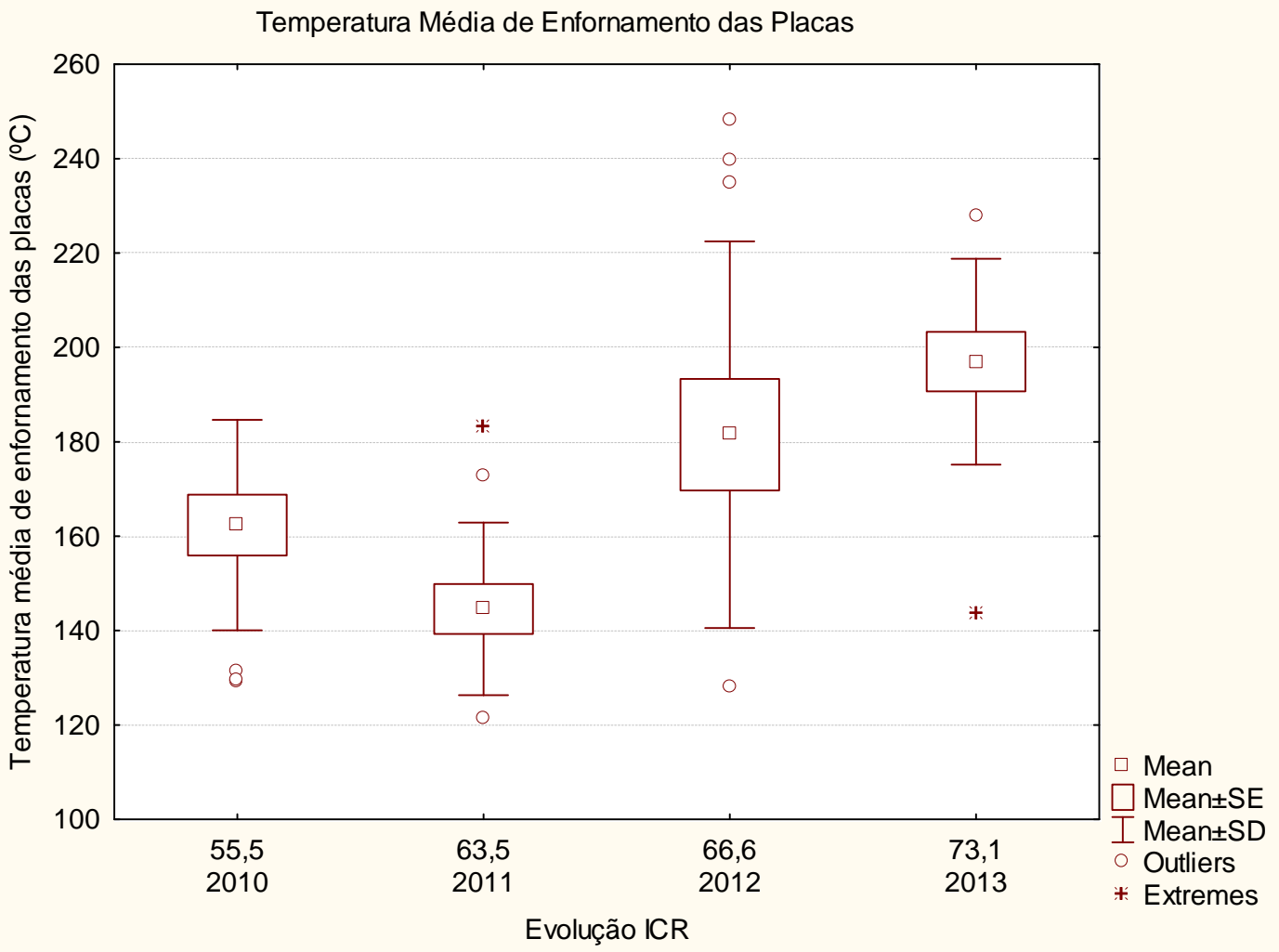

Figura 8. Evolução anual da temperatura média de enfornamento das placas.

* Contribuição técnica ao 450 Seminário de Aciaria - Internacional, 25 a 28 de maio de 2014, Porto Alegre, RS, Brasil. 


\section{DISCUSSÃO DOS RESULTADOS}

Embora sendo os principais motivos de desvio, as ocorrências de mudança de largura e evento de qualidade são muitas vezes inerentes ao processo. As reduções destes desvios foram, portanto, inferior a $50 \%$.

A mudança de largura em placas ocorre mediante programação, que por sua vez está relacionada ao tamanho dos pedidos do cliente. Diferentes pedidos têm larguras diferentes. No entanto almeja-se um seqüencial de 8 corridas por distribuidor, ou seja 2520 ton/ distribuidor. Em caso de pedidos inferiores a 2520 ton, é necessária a mudança de largura durante lingotamento. Desta forma, a produção de placas com formato trapezoidal não pode ser eliminada. O foco foi aumentar a capacidade do LTQ em absorvê-las, aumentando a tolerância da intensidade do taper.

Grande parte dos eventos de qualidade é inerente ao processo. São exemplos as placas de partida e encerramento de sequência (placas críticas) e placas produzidas sob troca automática de válvula submersa, necessárias para o aumento do número de corridas por distribuidor.

O ganho no ICR se deu principalmente pela flexibilização da instrução de escarfagem preventiva em placas com eventos de qualidade, tais como variações anormais de desvio do nível do molde e de vazão de argônio, onde as placas que continham estes eventos passaram a ser enviadas diretamente para o LTQ. Vale ressaltar que possíveis impactos negativos relativos à flexibilização de escarfagem foram contornados pela intensificação de inspeção em bobinas (100\% das bobinas são inspecionadas automaticamente pelo sistema Parsytec), evitando a geração de problemas (esfoliação) nas etapas subsequentes de laminação a frio ou de processamento no cliente.

Os desvios devido rebarba em placas foram praticamente eliminados. Primeiramente foi importante avaliar a performance dos desrebarbadores de ambas as máquinas. Verificou-se que o desrebarbador da Máquina de Lingotamento Contínuo1 (MLC1) apresentou boa performance (acima de 95\%) para aços ultra baixo, baixo, peritético e médio carbono. Na MLC2, a performance era deficiente para aços peritéticos ou com carbono acima 0,085\%, mesmo com lâminas novas. Foi tomada a decisão de orientar a produção de aços peritéticos e médio carbono para a MLC1.

O plano de manutenção dos rebarbadores também foi intensificado, trocando-se todo o conjunto de lâminas mensalmente, diferente das 3 trocas anuais, anteriormente.

Os desvios de placa devido à indisponibilidade de ponte rolante do LTQ ocorrem quando as mesmas estão executando outras atividades como enfornamento para laminação e montagem dos pedidos. Estes desvios são pronunciados quando as máquinas 1 e 2 produzem placas para o LTQ simultaneamente. Desta forma, a produtividade das máquinas é maior que a capacidade das pontes do LTQ de recebê-las.

Para minimizar estes desvios, objetivou-se enviar placas sucessivas de mesma largura, possibilitando que a ponte do LTQ capture 2 placas em cada viagem e minimizando o seu trabalho. Foi necessário o envio, pelo contínuo, de duas placas consecutivas do mesmo veio, haja vista que na maioria das vezes as larguras diferem entre os veios.

Outro ponto importante foi a montagem de instruções grandes, maior que 140 placas. Desta forma, embora seja necessário um tempo maior para cada montagem,

* Contribuição técnica ao 45 Seminário de Aciaria - Internacional, 25 a 28 de maio de 2014, 


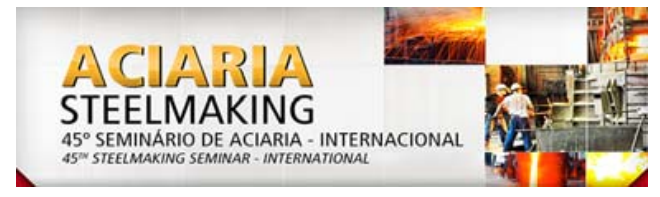

são necessárias menos montagens de instrução por dia, cerca de 3. Elas podem ser feitas em situações de menor demanda, no caso de parada de uma das máquinas.

Também aumentou-se a quantidade de posições disponíveis para placas ao longo da mesa do LTQ. Neste caso, o desvio de placas para o condicionamento inicia apenas quando houver 3 placas na extensão.

Após o início do projeto, em fevereiro de 2011, observou-se um aumento contínuo do índice de consecução de rota (ICR), atingindo o valor de 73,3\%. Este aumento permitiu ganhos relacionados ao custo de condicionamento (rendimento e mão de obra) e redução de energia no forno do LTQ, (aumento da temperatura média de enfornamento).

Observou-se que a taxa de enfornamento com temperatura superior a $200^{\circ} \mathrm{C}$ subiu de $30 \%$ para $40 \%$ comparando-se os anos de 2010 , antes do início do projeto, com 2013, após aumento significativo do ICR. Isto representou um aumento na temperatura média de enfornamento de $160^{\circ} \mathrm{C}$ para $200^{\circ} \mathrm{C}$, incremento de $40^{\circ} \mathrm{C}$. Conforme Shamanian [2], ganha-se $0,91 \mathrm{~kJ} / \mathrm{kg}$ a cada incremento de $1^{\circ} \mathrm{C}$ na temperatura de enfornamento da placa. Isto mostra que o ganho obtido é de $36,4 \mathrm{~kJ} /$ $\mathrm{kg}$ ou $8,7 \mathrm{kcal} / \mathrm{kg}$ ou $8,7 \mathrm{Mcal} / \mathrm{ton}$.

\section{CONCLUSÃO}

A partir deste projeto, foi observado um aumento significativo do percentual de placas com envio direto para o pátio do LTQ. Os ganhos apurados estão relacionados com redução do custo variável no condicionamento (redução de escarfagem) e redução do consumo de energia do forno do LTQ.

\section{REFERÊNCIAS}

1 Allwood JM et al. Going on a Metal Diet: using less liquid metal to deliver the same services in order to save energy and carbon. United Kingdom: University of Cambridge; 2011. p.4 .

2 Shamanian M, Najafizadeh A. Hot charge of continuously cast slabs in reheating furnaces. International Journal of ISSI. 2004;1(1):35-37.

3 Werkema,C. Criando a cultura seis sigma. Nova Lima: Werkema Ed.; 2004. p.184.

* Contribuição técnica ao $45^{\circ}$ Seminário de Aciaria - Internacional, 25 a 28 de maio de 2014, 